\title{
Changes in Glycosylated Hemoglobin in Short- and Semi Long-Term Streptozotocin-Diabetic Mice and Rats
}

\author{
Emiko FUJII and Teruko NOMOTO \\ Department of Pharmacology. Tokyo Women's Medical College. \\ 10 Kawada-cho. Shinjuku-ku, Tokyo 162, Japan \\ Accepted October 13, 1983
}

It is well known that glycosylated hemoglobin $\left(\mathrm{HbA}_{1}\right)$ increases in the blood of diabetic patients. However, only few studies have been reported on the changes in the values of $\mathrm{HbA}_{1}$ in mice and rats. The degree of increase in $\mathrm{HbA}_{1}$ levels was not correlated with the severity of hyperglycemia, duration of diabetes, age of the mouse, or body weight in C57BL/KsJ mice (1). In our previous paper, we reported that the $\mathrm{HbA}_{1}$ value increased in parallel with serum glucose level after streptozotocin (STZ), and the treatment with nicotinamide before STZ-injection abolished the increase of $\mathrm{HbA}_{1}$ in both STZtreated intact and thyroidectomized rats (2). The present study deals with the short- and semi long-term effects of experimental diabetes on the $\mathrm{HbA}_{1}$ and species differences between mice and rats with regard to these effects. Male ddY mice and Wistar-Imamichi rats were housed in an air-conditioned room (temperature $22 \pm 2{ }^{\circ} \mathrm{C}$, humidity $55 \pm 5 \%$ ) with

\section{(A) MICE}

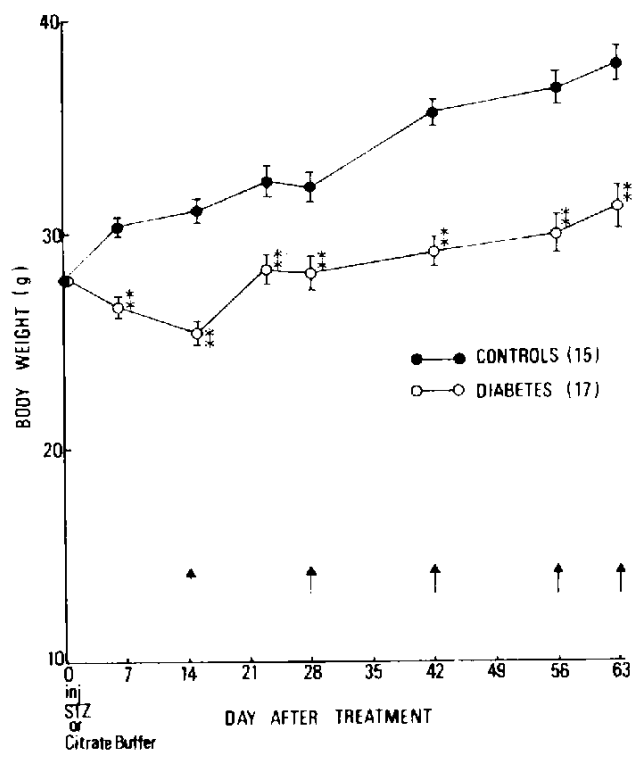

(B) RATS

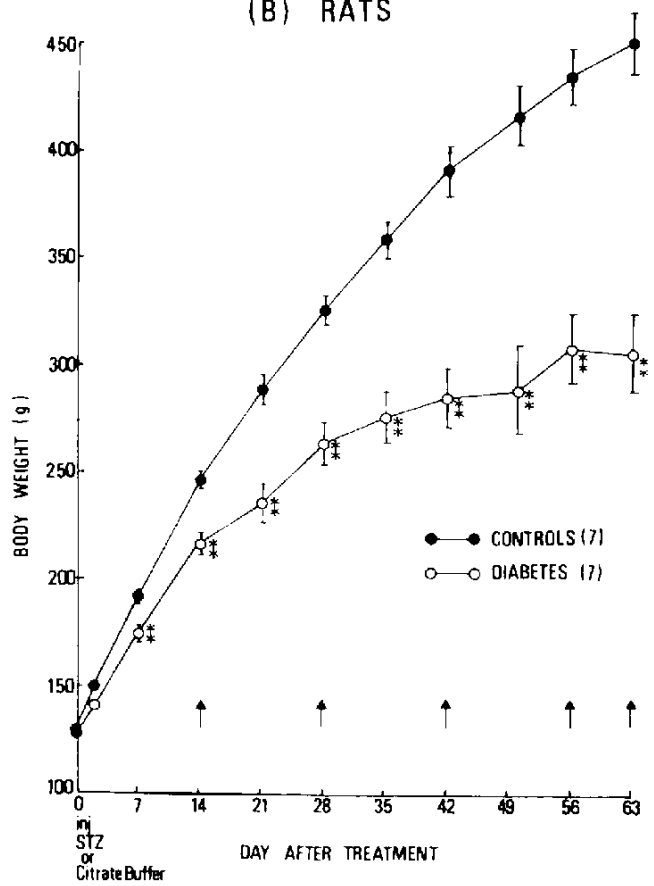

Fig. 1. Changes in body weight with increasing age and duration of experimental diabetes in mice (A) and rats $(B)$. Numbers of animals are shown in parentheses. Values shown are the mean $\pm S$. E. Controls: citrate buffer treated group. STZ: streptozotocin (170 mg/kg, i.p. in mice, $60 \mathrm{mg} / \mathrm{kg}$, i.v. in rats), $\uparrow$ : Collection of blood samples. P values were calculated by Student's $t$-test. ** $P<0.01$ : each citrate buffer group vs. STZ treated group. 
a controlled light-dark cycle (light on 06:0020:00) for one week before treatment. Food and water were available ad libitum. STZ (Sigma Chemical Co., U.S.A.), freshly dissolved in $0.1 \mathrm{M}$ citrate buffer ( $\mathrm{pH}$ 4.6). was injected intraperitoneally in mice (170 $\mathrm{mg} / \mathrm{kg}$, body wt.) and was injected into a saphenous vein of the hind-limb in rats $\langle 60$ $\mathrm{mg} / \mathrm{kg}$, body wt.). Control animals received a similar volume of citrate buffer. Body weights were determined once a week in this experimental period. Criteria for diabetes were the decrease in growth rate. glucosuria (determined by DIASTIX, Miles-Sankyo Co., Tokyo. Japan), and hyperglycemia. Blood samples were obtained from the neck of the animals immediately following the decapitation. The analyses of $\mathrm{HbA}_{1}$ and blood glucose were made $2,4,6,8$, and 9 weeks following the injection of STZ. HbA, was determined by the Quik-Sep method (Seikagaku Kogyo Co.. Tokyo, Japan) at $22-24^{\circ} \mathrm{C}$. Blood glucose was measured by the conventional method using the o-toluidine-boric acid reagent. The results were compared with those obtained in a control group. Data were

MICE

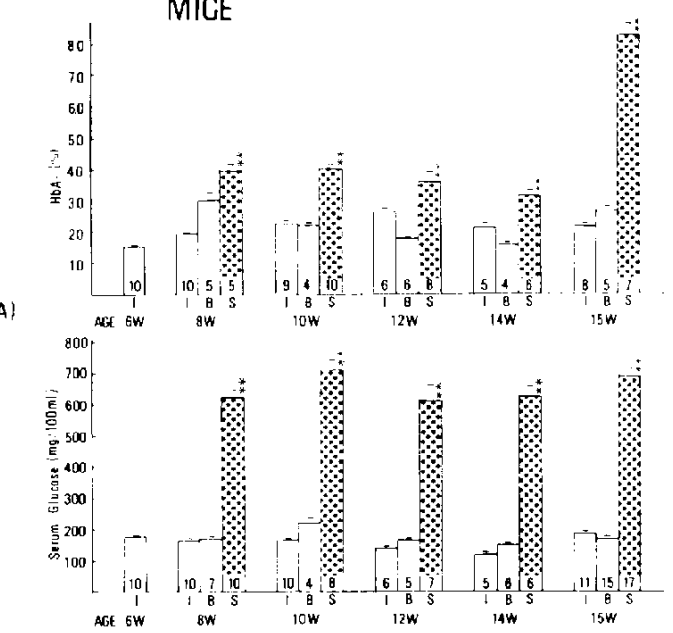

analyzed by Student's $t$-test; $P<0.05$ was considered to be significant.

As shown in Fig. 1, the increase in body weight was much reduced after STZ injection in mice (A) and rats (B) throughout the experimental period. The mean plasma glucose concentrations were 500 and 650 $\mathrm{mg} / \mathrm{dl}$ in diabetic rats and mice, respectively. which were quite high compared to the levels in control animals (Fig. 2A, B). HbA, values were also significantly increased in diabetic mice and rats throughout the experimental period; control animals averaged 1.6-3.0\% of total $\mathrm{Hb}$. while mean values in diabetic animals were in the range of $3.2-4.3 \%$ until 8 weeks following the injection of STZ. However, the $\mathrm{HbA}_{1}$ value in mice $(8.234 \pm$ $0.43 \%$ ) was significantly higher than that found in rats $(3.597 \pm 0.089 \%)$ after 9 weeks of STZ, and it was more than two-fold higher than that found in 8 weeks of STZ-diabetic mice.

It has recently been reported that $\mathrm{HbA}$, values of alloxan or STZ diabetic rats are about $4 \%$ at 8 and 12 months following the induction of diabetes (3). This value is very

\section{RATS}

(B)
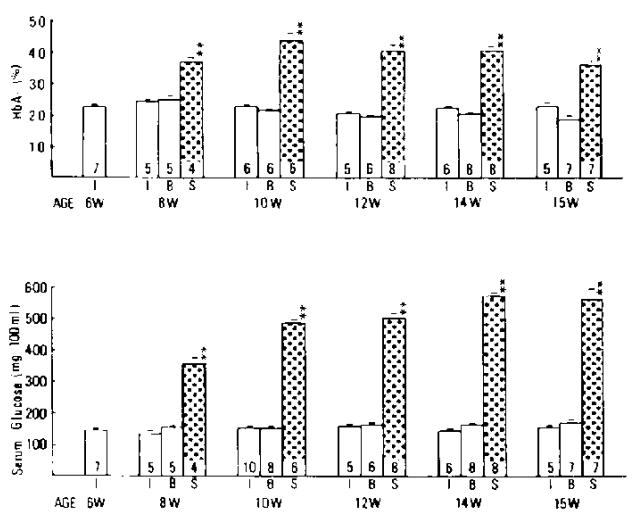

Fig. 2. Changes in glycosylated hemoglobin $A_{1}\left(H b A_{1}\right)$ and blood glucose (meanis.E.) in intact. buffer and streptozotocin treated diabetic mice (A) and rats (B). Numbers of animals in each group are indicated at the base of each column. I: intact group, B: citrate buffer treated group. S: streptozotocin treated group. AGE 6W: non-treated group. 8W: the group with two weeks after streptozotocin. 10W: the group with four weeks after streptozotocin. $12 \mathrm{~W}$ : the group with six wecks after streptozotocin, 14W: the group with eight weeks after streptozotocin. $15 \mathrm{~W}$ : the group with nine weeks after streptozotocin. $P$ values were calculated by Student's $t$-test. * $P<0.01$ : buffer group vs. streptozotocin group in mice and rats. 
close to our data obtained from STZ-treated rats at 8 or 9 weeks of diabetes. Therefore. the unexpectedly high value of $\mathrm{HbA}_{1}$ observed in STZ-diabetic mice at 9 weeks is noteworthy. However, it is not clear from our experimental conditions whether such a phenomenon is continuous or transient. The present results together with our previous paper (2) provides fundamental data for changes in $\mathrm{HbA}_{1}$ which have not been so intensively studied in the laboratory animals. On the other hand, they suggest that further long-term experiments are required for judging the species difference between mice and rats in the diabetic state.

\section{References}

1 Koenig, R.J., Araujo, D.C. and Cerami, A.: Increased hemoglobin $A_{1} c$ in diabetic mice. Diabetes 25, 1-5 (1976)

2 Fujii, E., Tsukahara, F. and Nomoto, T.: Effects of nicotinamide and insulin on glycosylated hemoglobin and blood glucose in thyroidectomized streptozotocin-diabetic rats. Japan. J. Pharmacol. 32, 903-907 (1982)

3 Moore, S.A., Peterson, R.G., Felten, D.L. and O'Connor, B.L.: A quantitative comparison of motor and sensory conduction velocities in short- and long-term streptozotocin- and alloxan -diabetic rats. J. Neurol. Sci. 48, 133-152(1980) 